\title{
Ailevi Akdeniz Ateşi Hastalarında MEFV Geninin NGS ile Analizi: Tek Merkez Deneyimi
}

\section{Analysis of the MEFV Gene by NGS in Patients with Familial Mediterranean Fever: A Single Center Experience}

\author{
Neslihan DÜZKALE TEKER ${ }^{1}{ }^{(\mathbb{D})}$, Özlem ÖZ ${ }^{2}$
}

\author{
1 S.B.Ü. Ankara Dışkapı Yıldııı Beyazıt Eğitim ve Araştırma Hastanesi, Tıbbi Genetik, Ankara, Türkiye \\ 2 Harran Üniversitesi Tıp Fakültesi, Tıbbi Genetik Anabilim Dalı, Şanlıurfa, Türkiye
}

öz.

Amaç: Ailevi Akdeniz ateşi (FMF) Akdeniz ülkelerinde sık görülen, otoinflamatuar multisistemik bir hastalıktır. MEFV geni, bu hastalıktan sorumlu tutulmuştur. Bu çalışmada FMF ön tanısı olan hastaların MEFV geninin yeni nesil dizileme (NGS) kullanılarak araştıııması amaçlanmıştır.

Materyal ve metod: Bu retrospektif çalışma 01.06.2018 - 01.07.2020 tarihleri arasında, Ankara Dışkapı Yıldııım Beyazıt Eğitim ve Araştırma Hastanesi, Tıbbi Genetik Bölümü'nde gerçekleşti. Çalışmada, FMF ön tanıı 220 hastanın NGS ile araştıııımış olan MEFV genine ait bulguları değerlendirilmiştir.

Bulgular: Çalışmadaki 220 hastanın (142 kadın, 78 erkek) yaş ortalaması 35,6 $\pm 11,4$ idi. Hastaların 131'nde (\%59) MEFV geninde varyant tespit edildi. Allel sayıları ve frekansları değerlendirildiğinde en sık tespit edilen varyantlar sırasıyla M694V, V726A, M680I ve E148Q olarak belirlendi. Hastalarda ayrıca nadir görülen varyantlar da tespit edildi. Tüm varyantların 152'si heterozigot, 20'si homozigot, 36'sı bileşik heterozigot ve 3'ü kompleks genotip durumundaydı.

Sonuç: Bu çalışmada elde edilen bulgular, Türkiye'den FMF hasta gruplarında daha önce bildirilen veriler ile uyumludur. Gerçekleştirilen NGS analizi, FMF hastalarında sık gözlenen MEFV gen varyantlarııın yanında, nadir varyantların saptanmasını da mümkün kıımıştır. Bu çalışma, Türkiye MEFV gen spektrumu verilerine katkı sağlayacaktır.

Anahtar Kelimeler: NGS, FMF, MEFV, M694V, E148Q

Abstract

Background: Familial Mediterranean fever (FMF) is an autoinflammatory multisystemic disease common seen in Mediterranean countries. The MEFV gene has been implicated in the disease. In this study, it was aimed to investigate the MEFV gene of patients with a pre-diagnosis of FMF by using NGS method.

Materials and Methods: This retrospective study was held between 01.06.2018 - 01.07 .2020 in Ankara Dışkapı Yıldırım Beyazıt Training and Research Hospital, Department of Medical Genetics. In this study, the findings of the MEFV gene of 220 patients with a pre-diagnosis of FMF, which were investigated by Next Generation Sequencing method, were evaluated.

Results: The mean age of 220 patients (142 women, 78 men) in the study was $35.6 \pm 11.4$ years. Variant was detected in the MEFV gene in $131(59 \%)$ of the patients. When allele numbers and frequencies were evaluated, the most frequently detected variants were M694V, V726A, M680I and E148Q, respectively. Of these variants, 152 were heterozygous, 20 were homozygous, 36 were compound heterozygous, and 3 were complex genotypes. Conclusion: The findings obtained in this study are consistent with data reported previously in patients with FMF group from Turkey. The performed NGS analysis made it possible to detect rare variants as well as the MEFV gene variants frequently observed in FMF patients. This work will contribute to the FMF gene Turkey spectral data.

Key words: NGS, FMF, MEFV, M694V, E148Q
Sorumlu Yazar I

Corresponding Author

Uzm. Dr. Neslihan DÜZKALE TEKER

\section{S.B.Ü. Ankara Dışkapı Yıldırım}

Beyazıt Eğitim ve Araştırma

Hastanesi,

Tıbbi Genetik Bölümü,

Ziraat Mahallesi,

06110, Altındağ/Ankara

e-mail: neslihanduzkale@gmail.com

Tel: +905057754500

Fax :+90 3125962308

Geliş tarihi / Received: 16.11.2020

Kabul tarihi / Accepted: 14.12.2020

DOI: 10.35440/hutfd.826687 


\section{Giriş}

Ailevi Akdeniz ateşi (FMF), tekrarlayan ateşin en yaygın kalıtsal nedeni olan monojenik otoinflamatuvar bir hastalıktır. FMF prevalansının, Doğu Akdeniz Bölgesi'nde yaşayan popülasyonlarda oldukça yüksek olduğu bildirilmiştir (1). Bu hastalık çoğunlukla Akdeniz'de yaşayanları etkilese de, son yüzyılda artan seyahat ve göçler nedeniyle dünya çapında görülmektedir. Türkiye populasyonunda FMF prevalansının yaklaşık $1 / 1000$ ve taşıyıcılık oranının ise $1 / 5$ olduğu saptanmıştır (2).

FMF klinikte tipik olarak, akut faz yanıt artışına eşlik eden ateş ve kendi kendini sınırlayan steril peritonit, artrit ve/veya plörezi şeklinde gözlemlenen serozal inflamasyon atakları ile karakterizedir. Bu hastalı̆ı̆ın en önemli komplikasyonu, uzun vadeli morbidite ve mortaliteden sorumlu olan amiloidozdur (3). Amiloidoz gelişimi için risk faktörleri başlıca erkek cinsiyet, artrit, tanıda gecikme, M694V homozigot genotip ve ailede amiloidoz öyküsüdür (4).

FMF'in kalitımı her ne kadar otozomal resesif olarak bilinse de, bazı heterozigot bireylerin hastalığa spesifik olan fenotipik özellikleri sergilediği ve kolşisine iyi yanıt verdiği bilinmektedir $(5,6)$. Bu hastalıktan sorumlu olan MEFV geni, 16.kromozom üzerinde lokalizedir ve 781 aminoasit büyüklüğündeki pirin proteinini kodlamaktadır. Bu immün regülatuar protein, inflamasyon oluşumunu tetikleyen ve inflamatuar aracıların üretimini sağlayan doğal bir bağışıklık sensörü olarak işlev görür (7). Pirin çoğunlukla nötrofiller, eozinofiller, monositler, dendritik hücreler ve fibroblastlarda ifade edilir ve apoptoz, inflamasyon, sitokin üretiminin düzenlenmesinde rol oynar (8). Bu proteinin yapısındaki değişimler, kontrolsüz interlökin-1 (IL-1) salgılanmasına ve inflamatuar yanıtta artışa neden olur (9).

MEFV geninde şimdiye kadar birçok hastalık ilişkili varyant tanımlanmışır ve bunların çoğunlukla bu genin 10. ekzonunda yerleştiği gözlenmiştir (10). Akdeniz bölgesinde yaşayan populasyonun, MEFV geninde tespit edilen mutasyonların yaklaşık \%80'ini, ekzon 10'da lokalize olan M680I, M694V, M694I, V726A missense mutasyonları oluşturmaktadır (11). Bu retrospektif çalışmada, FMF şüphesi olan 220 hastanın, MEFV gen varyantları, NGS yöntemi ile analiz edilerek değerlendirilmiştir. Amacımız, merkezimizdeki MEFV gen varyantlarının sıklığının ve spektrumunun belirlenerek, Türkiye populasyonunun MEFV genetik verilerine katkı sağlamaktır.

\section{Materyal ve Metod}

1 Ocak 2015- 30 Nisan 2019 tarihleri arasında TM anterior Çalışma, 01.06.2018 - 01.07.2020 tarihleri arasında, Ankara Dışkapı Yıldırım Beyazıt Eğitim ve Araştırma Hastanesi Tıbbi Genetik polikliniğinde gerçekleştirildi. Tell Hashomer Kriterleri'ne uygun olarak (12), FMF şüphesi ile analiz edilmiş olan toplam 220 hasta araştırmaya dahil edildi.
Incelenen hasta populasyonu, aralarında akrabalık olmayan bireylerden oluşmaktaydı. Hastaların yaş, cinsiyet ve MEFV geni analiz sonuçları retrospektif olarak incelendi. Tüm hastalar, bu çalışmada bilgilerinin kullanıımasına izin verdi. Bu retrospektif çalışma; Dünya Tıp Birliği ve Helsinki Bildirgesi'ne göre etik sorumluluklar dikkate alınarak gerçekleştirildi ve Ankara Dışkapı Eğitim ve Araştırma Hastanesi'nin bağımsız Etik Kurulu tarafından onaylandı (Protokol no: 2020- 94/01).

MEFV analizi için hastalardan $2 \mathrm{ml}$ periferik venöz kan örnekleri alınarak Etilen Diamin Tetra Asetikasit'li (EDTA) tüplere konuldu. Genomik materyal, otomatik DNA izolasyon sistemi olan QIAcube ${ }^{\circledR}$ (Qiagen Inc. Mississauga, ON, Canada) ile izole edildi. Elde edilen DNA'ların konsantrasyonu ve kalitesini değerlendirmede bir spektrofotometrik ölçüm cihazı olan ND-1000 (Nano-Drop Technologies, Wilmington, $D E, A B D$ ) kullanıldı. Analiz için uygun saflık ve konsantrasyona (OD260/OD280, 1.8-2.0) sahip olan DNA'lar çalışmaya dahil edildi.

Analiz için NGS yöntemi kullanıldı. Bu yöntem, hastalık ile ilişkilendirilmiş olan gen bölgesinin polimeraz zincir reaksiyonu ile çoğaltılması ve çoğaltılan bölgelerin NGS teknolojisi kullanılarak dizilenmesini içermektedir. Çalışma; FMF MASTR Dx Assay (Multiplicom) kiti kullanılarak, Illumina MiSeq ${ }^{\circledR}$ sisteminde gerçekleştirildi. Analizde, MEFV genine ait tüm kodlayan bölgeler ve ekzon-intron birleşimindeki 25 baz çifti incelenmiş̧ir. Çalışma sonucunda tespit edilen veriler, "Sophia DDM 5.2.1®" biyoinformatik analiz programı kullanılarak "hg19 insan genomu" ile karşılaştırıldı. MEFV gen analizinde erişim numarası, NM_000243.3 olarak kabul edildi. Elde edilen sekans varyantları, ACMG (American College of Medical Genetics and Genomics) kIlavuzundaki algoritmalar takip edilerek sınıflandırıldı (13). İstatiksel analiz: Verilerin istatistiksel analizi için, SPSS (Statistical Package For Social Sciences for Windows v.22,0, SPSS Inc. Chicago, IL) programı kullanıldı. Tanımlayıcı istatistikler; ortalama $( \pm)$, standart sapma, frekans dağılımı ve yüzde olarak hesaplandı.

\section{Bulgular}

Çalışmaya FMF şüphesi ile MEFV analizi yapılan toplam 220 hasta (142 kadın, 78 erkek) dahil edilmiştir. Hastaların yaş ortalaması $35,6 \pm 11,4$ idi. Analiz sonucunda 131 $(\% 59,5)$ hastada MEFV geninde varyant tespit edildi. Varyant tespit edilen $78(\% 59,5)$ hasta kadın, $53(\% 40,5)$ hasta ise erkek cinsiyette idi ve bunların yaş ortalamaları $35,02 \pm 11,08$ olarak hesaplandı. Tüm hastaların gen analiz sonuçları Şekil 1'de özetlenmiştir.

MEFV gen varyantı tespit edilen 131 hastanın allel sayıları ve frekansları değerlendirildiğinde en sık gözlenen varyantın M694V olduğu saptandı. Bunu sırasıyla V726A, M680I,E148Q, R761H, L110P, P369S, R408Q, S749L, R653H, T267I, K695R, E167N, G304R, E520V, I591T, A744S, S166L varyantları takip etti (Tablo 1). 


\section{Genotip dağılımı}

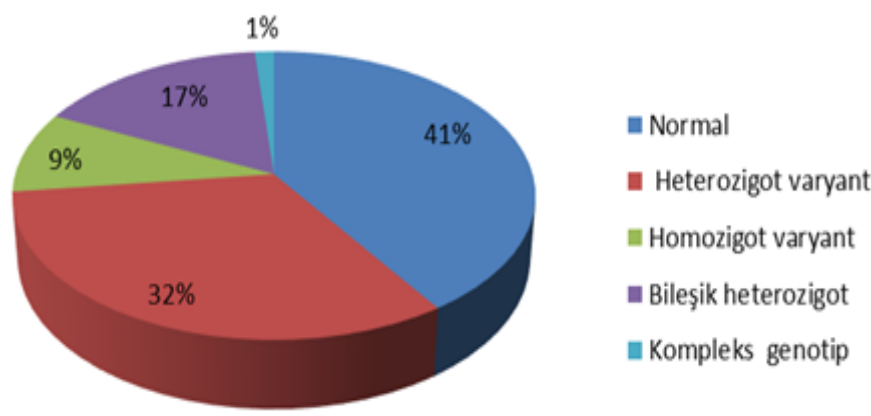

Şekil 1. Hastaların genotip sonuçları

Tablo 1. 1 MEFV gen mutasyonları tespit edilen 131 hastanın allel frekansları

\begin{tabular}{|c|c|c|c|c|c|c|c|}
\hline Varyant & $\begin{array}{l}\text { Ekzonik } \\
\text { Lokalizasyon }\end{array}$ & Nükleotid değişimi & Protein değişimi & Varyant tipi & ACMG Sınıflama & $\begin{array}{l}\text { Allel } \\
\text { sayısı }\end{array}$ & $\begin{array}{l}\text { Allel Frekansı } \\
\text { (\%) }\end{array}$ \\
\hline M694V & 10 & c. $2080 A>G$ & p.Met694Val & $\mathrm{M}$ & $P$ & 90 & 46,6 \\
\hline V726A & 10 & c. $2177 \mathrm{~T}>\mathrm{C}$ & p.Val726Ala) & M & $\mathrm{P}$ & 28 & 14,5 \\
\hline M680I & 10 & c. $2040 \mathrm{G}>\mathrm{A}$ & p.Met680lle & M & $\mathrm{P}$ & 27 & 14,0 \\
\hline R761H & 10 & c. $2282 \mathrm{G}>\mathrm{A}$ & p.Arg761His & M & $\mathrm{P}$ & 4 & 2,1 \\
\hline S749L & 10 & c.2245 2246del & p.Ser749Leu & M & $P$ & 2 & 1,0 \\
\hline R653H & 10 & c. $1958 \bar{G}>A$ & p.Arg653His & M & $\mathrm{P}$ & 2 & 1,0 \\
\hline K695R & 10 & c. $2084 A>G$ & p.Lys695Arg & M & MP & 2 & 1,0 \\
\hline A744S & 10 & c. $2230 \mathrm{G}>\mathrm{T}$ & p.Ala744Ser & M & $\mathrm{P}$ & 1 & 0,5 \\
\hline I591T & 9 & c. $1772 T>C$ & p.lle591Thr & M & VUS & 1 & 0,5 \\
\hline E520V & 5 & c. $1559 A>T$ & p.Glu520Val & M & VUS & 1 & 0,5 \\
\hline P369S & 3 & c. $1105 \mathrm{C}>\mathrm{T}$ & p.Pro369Ser) & M & VUS & 3 & 1,6 \\
\hline R408Q & 3 & c.1223G $>A$ & p.Arg408GIn & M & VUS & 3 & 1,6 \\
\hline T2671 & 2 & c. $800 \mathrm{C}>\mathrm{T}$ & p.Thr267lle & M & MP & 2 & 1,0 \\
\hline E167N & 2 & $\begin{array}{l}\text { c.499_501delGAGin } \\
\text { sAAC }\end{array}$ & p.Glu167Asn & M & VUS & 1 & 0,5 \\
\hline G304R & 2 & $c .910 \mathrm{G}>\mathrm{A}$ & p.Gly304Arg & M & MP & 1 & 0,5 \\
\hline E148Q & 2 & c. $442 G>C$ & p.Glu148Gln & M & VUS & 20 & 10,4 \\
\hline L110P & 2 & c. $329 \mathrm{~T}>\mathrm{C}$ & p.Leu110Pro & M & VUS & 4 & 2,1 \\
\hline S166L & 2 & c. $497 \mathrm{C}>\mathrm{T}$ & p.Ser166Leu) & M & VUS & 1 & 0,5 \\
\hline Toplam & & & & & & 193 & 100 \\
\hline
\end{tabular}

Bu varyantlar; 152 hastada heterozigot, 20 hastada homozigot, 36 hastada bileşik heterozigot ve 3 hastada kompleks genotip durumda idiler. En sık görülen heterozigot varyantlar sırasıyla M694V, V726A, M680I, E148Q, R761H,
L110P, P369S, R408Q, S749L, R653H, T267I, K695R, E167N, G304R, E520V, I591T ve A744S olarak tespit edildi. En sık gözlenen homozigot varyantlar sırasıyla M694V, M680I, E148Q, R653H olarak belirlendi (Tablo 2).

Tablo 2. Heterozigot ve homozigot varyantların dağıımı

\begin{tabular}{lll}
\hline Genotip & $\begin{array}{l}\text { Heterozigot } \\
\mathrm{n}(\%)\end{array}$ & $\begin{array}{l}\text { Homozigot } \\
\mathrm{n}(\%)\end{array}$ \\
\hline M694V & $58(\% 38,2)$ & $16(\% 80)$ \\
V726A & $28(\% 18,4)$ & - \\
M680I & $23(\% 15,1)$ & $2(\% 10)$ \\
E148Q & $18(\% 11,8)$ & $1(\% 5)$ \\
R761H & $4(\% 2,6)$ & - \\
L110P & $4(\% 2,6)$ & - \\
P369S & $3(\% 2,0)$ & - \\
R408Q & $3(\% 2,0)$ & - \\
S749L & $2(\% 1,3)$ & - \\
R653H & - & $1(\% 5)$ \\
T267I & $2(\% 1,3)$ & - \\
K695R & $2(\% 1,3)$ & - \\
E167N & $1(\% 0,7)$ & - \\
G304R & $1(\% 0,7)$ & - \\
E520V & $1(\% 0,7)$ & - \\
I591T & $1(\% 0,7)$ & - \\
A744S & $1(\% 0,7)$ & $20(\% 100)$ \\
\hline Toplam & $152(\% 100)$ & \\
\hline
\end{tabular}


Hastalarda en sık gözlenen bileşik heterozigot varyantlar ise M694V/M680I ve M694V/V726A idi (Tablo 3).

Tablo 3. Bileşik heterozigot hastalarda genotiplerin dağılımı

\begin{tabular}{ll}
\hline Genotip & Bileşik heterozigot $\mathbf{n}(\%)$ \\
\hline M694V/M680I & $7(\% 19,4)$ \\
M694V/V726A & $6(\% 16,7)$ \\
M680I/V726A & $5(\% 13,9)$ \\
E148Q/M694V & $5(\% 13,9)$ \\
E148Q/L110P & $3(\% 8,3)$ \\
E148Q/M680I & $2(\% 5,6)$ \\
P369S/R408Q & $2(\% 5,6)$ \\
V726A/T267I & $2(\% 5,6)$ \\
R761H/M680I & $1(\% 2,8)$ \\
E148Q/V726A & $1(\% 2,8)$ \\
R761H/M694V & $1(\% 2,8)$ \\
E148Q/E520V & $1(\% 2,8)$ \\
\hline Toplam & $36(\% 100)$ \\
\hline
\end{tabular}

Çalışmada ayrıca kompleks genotipe sahip olan 3 hasta tespit edildi (Tablo 4).

Tablo 4. Kompleks genotipe sahip hastalarda genotiplerin dağıIımı

\begin{tabular}{ll}
\hline Genotip & $\mathbf{n}$ \\
\hline E148Q + M694V + V726A & 1 \\
E167N + S749L + M694V & 1 \\
E148Q + P369S + R408Q + M694V & 1 \\
\hline Toplam & 3 \\
\hline
\end{tabular}

Hastalar tek allelde heterozigot mutasyon bulunma durumuna göre değerlendirildiğinde en sık tespit edilen genotiplerin M694V/WT ve M680I/WT olduğu görüldü (Tablo 5).

Tablo 5. Tek allelde heterozigot varyant bulunan genotiplerin dağılımı

\begin{tabular}{ll}
\hline Genotip & $\mathbf{n}(\%)$ \\
\hline M694VI WT & $35(\% 49,3)$ \\
V726A/ WT & $14(\% 19,7)$ \\
M680I/ WT & $8(\% 11,3)$ \\
E148Q/ WT & $4(\% 5,6)$ \\
K695R/ WT & $2(\% 2,8)$ \\
R761H/ WT & $3(\% 4,2)$ \\
A744S/ WT & $1(\% 1,4)$ \\
S166L/ WT & $1(\% 1,4)$ \\
I591T/ WT & $1(\% 1,4)$ \\
L110P/ WT & $1(\% 1,4)$ \\
S749L/ WT & $1(\% 1,4)$ \\
\hline Toplam & $71(\% 100)$ \\
\hline WT: Wild Tip &
\end{tabular}

\section{Tartışma}

Çalışmamızda 220 hastanın 131 'inde 18 farklı varyant bulundu. En sık sık görülen varyantlar ve allel frekanslarl; M694V (\%46,6), V726A (\%14,5), M680I (\%14,0), E148Q $(\% 10,4)$ olarak belirlendi.

MEFV'in bilinen 300'den fazla sekans varyantı vardır, ancak FMF'de yalnızca 14'ü (E148Q, E167D, T267I, P369S, F479L, I591T, M680I, I692del, M694I, M694V, K695R, V726A, A744S, R761H) yaygın olarak bulunur. Bu varyantların \%80'i ekzon 10'da ve diğerleri çoğunlukla ekzon 2, 3 ve 5 'te yerleşmişlerdir (12). FMF'in sık görüldüğü coğrafi bölgelerde MEFV genindeki varyantların \%85'ini M694V, M680I(G/C), M694I, V726A oluşturmaktadır. Türkiye populasyonunda daha önceden yapılan çalışmalarda, FMF fenotipi olan hastalarda en sık gözlenen varyantlar M694V, E148Q, M680I(G/C) ve V726A olarak rapor edilmiştir (14). Çalışmamızda en sık görülen varyant \% 46,6 $(n=90)$ allel frekans oranı ile M694V idi. Türkiye populasyonunda, M694V mutasyonu genel sıklı̆ı \% 23,5 olarak bildirilmiştir (14).

Çalışmamızda, 71 hasta MEFV heterozigot olarak saptandı. MEFV heterozigotlarının çoğu yaşam boyunca asemptomatiktir. Bununla birlikte, penetrasyonu yüksek olan bazı patojenik varyantlara sahip heterozigotlar semptomatik olabilir ve bu taşıyıcılar için, kalıtımın otozomal dominant olabileceği düşünülmektedir. Literatürde, penetrasyonu yüksek ve ekzon 10'da lokalize olan 3 patojenik varyant tanımlanmıştır. Bunlar; p.Met694del, p.lle692del ve p.Tyr688Ter'dir $(15,16)$. Ayrıca, FMF için otozomal dominant kalıımın görüldüğü, yüksek penetrasyonlu p.Met694Val (en yaygın Akdeniz varyantı) ve p.Thr577Asn varyantlarının heterozigot olarak tespit edildiği aileler de bildirilmiştir (17).

Heterozigotlar tipik olarak, biallelik patojenik varyantları olan kişilere göre daha geç bir başlangıç yaşına (ortalama 18 yaş) ve daha hafif klinik bulgulara (esas olarak ateş ve abdominal semptomlarla kendini gösterir) sahiptir. Literatürde yapılan bir çalışmada, heterozigotların çoğunda hastalığın ana bulgusu, inkomplet abdominal ataklar (peritonit gelişmeyen karın ağrısı) idi ve bu bireylerin büyük kısmında kolşisin tedavisine tam veya kısmi yanıt vardı (5). Başka bir çalışmada, heterozigot MEFV patojenik varyantı olan 18 kişiden beşinde FMF'nin klinik belirtilerinin ergenlik çağında tamamen ortadan kalktığı ve semptomların nüksetmeden kolşisini bırakmalarına izin verildiği gözlendi (18). Heterozigot MEFV genotipine sahip bireylerin, normal genotipli olanlara kıyasla akut faz reaktanlarının bazal ve pik düzeylerinin daha yüksek olduğu gözlemlenmiş ve bu taşıyıcılarda bir "proinflamatuar fenotip" olduğu düşünülmüştür (19). Bir çalışmada, akut romatizmal ateş, artralji, romatoid artrit ve yılda en az dört kere olan febril atakların, FMF'li çocukların asemptomatik heterozigot ebeveynlerinde daha sık gözlendiği bildirilmiştir (20).

Bir başka çalışmada; MEFV genindeki yüksek penetranslı mutasyonların, düşük penetranslılara kıyasla klinik bulgulara daha fazla sebebiyet vermesi nedeniyle, mutasyonların "doz etkisi" olduğu ifade edilmiştir (21). Örneğin, daha şiddetli ve erken başlangıçlı hastalık; M694V homozigot hastalar ile M694V bileşik heterozigot olanlarda daha sıklıkla görülür (22). Hatta, M694V mutasyonları için homozigot olan hastalar, diğer genotiplere kıyasla 6 kat daha yüksek amiloidoz riski taşır (4). Yapılan çalışmalar, sadece M694V değil aynı zamanda ekzon 10'da, 694-680 pozis- 
yon aralığında lokalize olan tüm homozigot veya bileşik heterozigot mutasyonların, bireyde daha şiddetli bir fenotip oluşturma riskini artırdığını göstermiştir (12).

Hasta grubumuzda E148Q varyantı, 18 hastada heterozigot ve 1 hastada homozigot olarak saptandı. 18 hastanın 12 'si bileşik heterozigot ve 2'si ise kompleks genotipe sahipti. M694V'den sonra en yaygın olan varyantlardan biri olan ekzon 2'deki E148Q'nun FMF'deki patojenik rolü hala belirsizdir. Sağlıklı popülasyonda \%1'den fazla bireyin bu varyantı taşıması, iyi huylu bir polimorfizm olabileceğini düşündürmektedir (23) ve bazı çalışmalar, E148Q'nun klinik önemi bilinmeyen bir varyant olduğunu öne sürmektedir (24).

Bir vaka-kontrol çalışmasında, E148Q'nun, işlevsel etkisi olmayan bir dizi varyantı olabileceği tespit edilmiş̧ir. Sözkonusu çalışmada, hastalar ve sağ|ıklı kontroller arasında ve hastalar ile asemptomatik akrabaları arasında benzer bir E148Q mutasyon frekansı bulunmuş olup, FMF olan ve olmayanlar arasında da M694V/E148Q genotip sıklığı aynı oranda saptanmıştır. Ve yazarlar, E148Q'nun hem heterozigot hem de homozigot hastalarda hastalığa neden olmayan bir varyant olduğu sonucuna varmışlardır (25).

Bazı yazarlar ise E148Q'u, işlevsel bir polimorfizm olarak kabul ederek genellikle hafif bir fenotip sunan atipik FMF ile ilişkili olduğunu savunmuşlardır. Aynı zamanda diğer tekrarlayan ateş ve inflamasyon sendromları ile de bu varyantı ilişkilendirmişlerdir (26). Bununla birlikte, E148Q'nun M694V gibi yüksek penetranslı varyantlarla birlikteyken olan fonksiyonel önemi halen aydınlatılamamıştır. Bu varyantın bileşik heterozigot hastalarda veya kompleks allellerde patojenik etkiyi güçlendiren bir rol oynayabileceği düşünülmüştür $(25,27)$. Sonuç olarak, E148Q varyantı yaygındır, patojenik önemi bilinmemektedir ve tek MEFV varyantı olarak FMF tanısını desteklememektedir (12).

Çalışmamızda ikinci en sık görülen varyant V726A idi ve $\% 14,5(n=28)$ allel frekans oranı tespit edildi. Bu varyant Türkiye populasyonunda yapılan birçok çalışmada dördüncü en yaygın mutasyon olarak bildirilmiştir (14). V726A aynı zamanda Orta Doğu popülasyonlarında en yaygın mutasyonlardan biridir ve klasik FMF fenotipi ile ilişkilidir $(26,28)$.

Bu araştırmadaki üçüncü yaygın mutasyon $\% 14,0(n=27)$ allel frekans oranı ile M680I (G/C) olarak bulundu. Bu varyant hem Türkiye popülasyonunda hem de Ortadoğu ülkeleri ve Ermenistan'da yaygın görülen bir mutasyon olarak bilinmektedir (26). Çalışmada ayrıca tespit edilen; $\mathrm{R} 761 \mathrm{H}$, L110P, P369S, R408Q, S749L, R653H, T267I, K695R, E167N, G304R, E520V, I591T, A744S, S166L varyantları çalışmanın nadir mutasyonlarıydı. Çalışmamızda saptanan S749L ve E167N genomik değişimleri, literatürde daha önceden rapor edilmemişti. Türkiye'nin farklı bölgelerine göre nadir mutasyonların verileri farklıık göstermektedir (2, 14).
Hastalığın etyopatogenezinin anlaşılmasında yeni bir bakış açısı kazandıran NGS yönteminin rutin klinik laboratuvarlara uyarlanması ve bu sayede daha fazla gen bölgesinin analiz edilebilmesi, yeni populasyon verilerinin elde edilmesini mümkün kılacaktır. Karacan ve ark.; FMF'in de dahil edildiği, sistemik otoinflamatuar klinik bulgusu olan birçok hasta örneği ile gerçekleştirdikleri çalışmalarında, Sanger dizileme tekniğine kıyasla, NGS analizinin daha yüksek bir moleküler tanı oranı sağladığını bildirmişlerdir (29). Bozgeyik ve ark. ise, FMF hastalarında NGS yöntemi ile MEFV geninde daha önce tanımlanmamış iki yeni mutasyon (GIn34Pro ve lle247Val) bildirmişlerdir (30).

Rutin laboratuarlar, MEFV gen analizinde NGS yerine çoğunlukla, 12 mutasyonun (E148Q, P369S, F479L, M680I (G/C), M680I (G/A), I692del, M694V, M694I, K695R, V726A, A744S ve R761H) hedeflendiği bir paneli kullanmaktadırlar. Bu panel daha az maliyetli olsa da NGS'e göre daha az bölgeyi kapsamaktadır. Literatürde FMF hastaları ile yapılan bir çalışmada, 12-mutasyon hedefli panelin, NGS ile saptanan genomik değişimlerin yalnızca $1 / 3$ 'ünü tespit edebildiği rapor edilmiştir (31). Bizim çalışmamızı 12mutasyon hedefli panel yerine NGS ile gerçekleştirmemiz, literatürde daha önceden bildirilmiş olan R653H, I591T, E520V, R408Q, T267I, G304R, L110P ve S166L varyantları ile ilk kez bu çalışmada gözlenen S749L ve E167N novel varyantlarının tespit edilmesine olanak sağlamıştır.

Sonuç olarak, çalışmamızda NGS yöntemi kullanarak yapmış olduğumuz genetik analiz ile, rutin taramada incelenen bölgelerden farklı noktalarda da varyantlar tespit edilmiştir. Çalışmamızda elde edilen bulgular, çok sayıda etnik grup içeren ve oldukça heterojen yapıdaki Türkiye populasyonunun MEFV genetik verilerine katkı sağlayacaktır. Türkiye'nin MEFV gen spektrumunun tanımlanmasında geniş hasta serilerinin dahil edileceği büyük ölçekli çalışmalara intiyaç vardır.

Etik onam: Çalışmanın için etik onam Ankara Dışkapı Eğitim ve Araştırma Hastanesi Klinik Araştırmalar Etik Kurulu tarafından 24/08/2020 tarihinde alınmıştır (Karar no: 202094/01).

\section{Kaynaklar}

1. Ozen S, Karaaslan Y, Ozdemir O, Saatci U, Bakkaloglu A, Koroglu E, et al. Prevalence of juvenile chronic arthritis and familial Mediterranean fever in Turkey: a field study. J Rheumatol. 1998;25(12):2445-9.

2. Tunca M, Akar S, Onen F, Ozdogan H, Kasapcopur O, Yalcinkaya F, et al. Familial Mediterranean fever (FMF) in Turkey: results of a nationwide multicenter study. Medicine (Baltimore). 2005;84(1):1-11.

3. Twig G, Livneh A, Vivante A, Afek A, Shamiss A, Derazne E, et al. Mortality risk factors associated with familial Mediterranean fever among a cohort of 1.25 million adolescents. Ann Rheum Dis. 2014;73(4):704-9.

4. Kasifoglu T, Bilge SY, Sari I, Solmaz D, Senel S, Emmungil H, et al. Amyloidosis and its related factors in Turkish patients with familial Mediterranean fever: a multicentre study. Rheumatology. 2014;53(4):7415.

5. Booty MG, Chae JJ, Masters SL, Remmers EF, Barham B, Le JM, et 
al. Familial Mediterranean fever with a single MEFV mutation: where is the second hit? Arthritis Rheum. 2009;60(6):1851-61.

6. Marek-Yagel D, Berkun Y, Padeh S, Abu A, Reznik-Wolf H, Livneh $A$, et al. Clinical disease among patients heterozygous for familial Mediterranean fever. Arthritis Rheum. 2009;60(6):1862-6.

7. Masters SL, Lagou V, Jéru I, Baker PJ, Van Eyck L, Parry DA, et al. Familial autoinflammation with neutrophilic dermatosis reveals a regulatory mechanism of pyrin activation. Sci Transl Med. 2016;8(332):332ra45-ra45.

8. Mankan A, Kubarenko A, Hornung V. Immunology in clinic review series; focus on autoinflammatory diseases: inflammasomes: mechanisms of activation. Clin Exp Immunol. 2012;167(3):369-81.

9. Berkun Y, Padeh S, Reichman B, Zaks N, Rabinovich E, Lidar M, et al., editors. A single testing of serum amyloid a levels as a tool for diagnosis and treatment dilemmas in familial Mediterranean fever. Semin Arthritis Rheum. 2007;37(3):182-8.

10. Goulielmos G, Fragouli E, Aksentijevich I, Sidiropoulos P, Boumpas $D$, Eliopoulos E. Mutational analysis of the PRYSPRY domain of pyrin and implications for familial mediterranean fever (FMF). Biochem Biophys Res Commun. 2006;345(4):1326-32.

11. Ben-Chetrit E, Touitou I. Familial Mediterranean fever in the world. Arthritis Rheum. 2009;61(10):1447-53.

12. Giancane G, Ter Haar NM, Wulffraat N, Vastert SJ, Barron K, Hentgen $\mathrm{V}$, et al. Evidence-based recommendations for genetic diagnosis of familial Mediterranean fever. Ann Rheum Dis. 2015;74(4):635-41.

13. Richards S, Aziz N, Bale S, Bick D, Das S, Gastier-Foster J, et al. Standards and guidelines for the interpretation of sequence variants: a joint consensus recommendation of the American College of Medical Genetics and Genomics and the Association for Molecular Pathology. Genet Med. 2015;17(5):405-23.

14. Kocakap DBS, Günel-Özcan A, Cabuk F, Ensari C. The frequency of Familial Mediterranean fever gene mutations and genotypes at Kirikkale and comparison with the mean of regional MEFV mutation frequency of Turkey. Mol Biol Rep. 2014;41(3):1419-26.

15. Rowczenio DM, lancu DS, Trojer H, Gilbertson JA, Gillmore JD, Wechalekar AD, et al. Autosomal dominant familial Mediterranean fever in Northern European Caucasians associated with deletion of p. M694 residue-a case series and genetic exploration. Rheumatology. 2017;56(2):209-13.

16. Bonyadi M, Esmaeili M, Jalali H, Somi M, Ghaffari A, Rafeey M, et al. MEFV mutations in Iranian Azeri Turkish patients with familial Mediterranean fever. Clin Genet. 2009;76(5):477-80.

17. Stoffels M, Szperl A, Simon A, Netea MG, Plantinga TS, van Deuren $\mathrm{M}$, et al. MEFV mutations affecting pyrin amino acid 577 cause autosomal dominant autoinflammatory disease. Ann Rheum Dis. 2014;73(2):455-61.

18. Hentgen V, Grateau G, Stankovic-Stojanovic $K$, Amselem S, Jéru I. Familial Mediterranean fever in heterozygotes: are we able to accurately diagnose the disease in very young children? Arthritis \& Rheumatism. 2013;65(6):1654-62.

19. Lachmann H, Şengül B, Yavuzşen T, Booth D, Booth S, Bybee A, et al. Clinical and subclinical inflammation in patients with familial Mediterranean fever and in heterozygous carriers of MEFV mutations. Rheumatology. 2006;45(6):746-50.

20. Kalyoncu M, Acar BC, Cakar N, Bakkaloglu A, Ozturk S, Dereli E, et al. Are carriers for MEFV mutations" healthy"? Clin Exp rheumatol. 2006;24(5 Suppl 42):S120-2.

21. Federici S, Calcagno G, Finetti M, Gallizzi R, Meini A, Vitale A, et al. Clinical impact of MEFV mutations in children with periodic fever in a prevalent western European Caucasian population. Ann Rheum Dis. 2012;71(12):1961-5.

22. Ozturk C, Halıcıoglu O, Coker I, Gulez N, Sutçuoglu S, Karaca N, et al. Association of clinical and genetical features in FMF with focus on MEFV strip assay sensitivity in 452 children from western Anatolia, Turkey. Clin Rheumatol. 2012;31(3):493-501.

23. Marek-Yagel D, Bar-Joseph I, Pras E, Berkun Y. Is E148Q a benign polymorphism or a disease-causing mutation? J Rheumatol. 2009;36(10):2372-.

24. Shinar Y, Obici L, Aksentijevich I, Bennetts B, Austrup F, Ceccherini I, et al. Guidelines for the genetic diagnosis of hereditary recurrent fevers. Ann Rheum Dis. 2012;71(10):1599-605.

25. Ben-Chetrit E, Lerer I, Malamud E, Domingo C, Abeliovich D. The E148Q mutation in the MEFV gene: is it a disease-causing mutation or a sequence variant? Hum Mutat. 2000;15(4):385-6.

26. Touitou I, Lesage S, McDermott M, Cuisset L, Hoffman H, Dode C, et al. Infevers: an evolving mutation database for auto-inflammatory syndromes. Hum Mutat. 2004;24(3):194-8.

27. Gershoni-Baruch R, Brik R, Shinawi M, Livneh A. The differential contribution of MEFV mutant alleles to the clinical profile of familial Mediterranean fever. Eur J Hum Genet. 2002;10(2):145-9.

28. Majeed HA, El-Khateeb M, El-Shanti H, Rabaiha ZA, Tayeh M, Najib $D$, editors. The spectrum of familial Mediterranean fever gene mutations in Arabs: report of a large series. Semin Arthritis Rheum. 2005;34(6):813-8

29. Karacan İ, Balamir A, Uğurlu S, Aydın AK, Everest E, Zor S, et al. Diagnostic utility of a targeted next-generation sequencing gene panel in the clinical suspicion of systemic autoinflammatory diseases: a multicenter study. Rheumatol Int. 2019;39(5):911-9.

30. Bozgeyik E, Mercan R, Arslan A, Tozkir H. Next-generation screening of a panel of genes associated with periodic fever syndromes in patients with familial Mediterranean Fever and their clinical characteristics. Genomics. 2020.

31. Gumus $E$. The frequency of MEFV gene mutations and genotypes in Sanliurfa province, South-Eastern region of Turkey, after the Syrian Civil War by using next generation sequencing and report of a Novel Exon 4 Mutation (I423T). J Clin Med. 2018;7(5):105 